OBSERVATIONS ON THE CAUSE AND TREATMENT OF INFANTILE ECZEMA AND ALLIED ERUPTIONS. ${ }^{\prime}$

\author{
BY HENRY T. BYFORD, M.D.,
}

\author{
OF CHICAGO.
}

In the winter of $\mathrm{I} 880$, I was called to attend Mrs. $\mathrm{R}$., in confinement with her fifth child. Two of her other four had been born dead; the other two, born apparently healthy, had died in convulsions at the ages of three and ten months. Both of the last had, before death, suffered from a scabby eruption, and become somewhat emaciated, but had not, as far as I could determine, been considered syphilitic. The child born at this time was, at first, apparently healthy, but, in a short time, broke out with an eruption that had the appearance of an ordinary ec\%ema pustulosum, and which affected its scalp and different parts of its body. The only other noticeable symptom was progressive emaciation.

A physician seeing the child for the first time at the age of three weeks, would have been excusable, without the family history, in considering this a strumous case, and in treating it with codl-liver oil. Minute doses of calomel and mercurial inunctions quickly transformed the unsightly, emaciated sufferer into a healthy, well-nourished infant.

In the summer of i 876 , I was called upon to treat a young child, Augustus G., with pustular eczema confined to the scalp, excessive nocturnal restlessness and progressive emaciation. 'This being the first chilk, there being neither copper-colored areolie nor other characteristics of a syphilide, but for the acknowledgment of the father of a former, but seemingly perfectly cured attack of syphilis (an acknowledgment not always made), mercurials would, as a rule, have been avoided by an attending physician. let the eczema rapidly disappeared, and the infant was soon gaining in thesh tupon calomel powders and mercurial inunctions.

To contrast with these syphilitic cases, I wish to relate another in which I know there was no possibility of a syphilitic taint, as I had been in daily communication with the father for three years before his marriage, and have often treated his family since. The patient, E. H., one year old, was unusually fat and well nourished, and had an eczema on the head which spread over the body in patches, in spite of the prolonged local treatment of one of our most in telligent practitioners. I recommended one-fifth of a grain of calomel to be given twice a day, and an ointment composed of one dram of carbolic acid in an ounce of the oxide of zinc ointment. After ten powders had been taken the eruption began to give up some of its area, and had almost disappeared by the time the thirty powders, first prescribed, were gone. Soon afterwards the eruption began to spread again, but was promptly cured by more of the powders. The child, having been overfed, was of course put upon a proper diet, by diluting the milk and infant food it was already taking, and withdrawing all other. The child has since remained well.

${ }_{1 R}$ Read before the Chicago Medical Society, on August 17, 1885 .
I have notes of a case of eczema, attended in I 880 , in which the eruption extended to the eyelids, causing such conjunctival sensitiveness that the child lay motionless in its cradle, with its eyes bandaged by day and night. Every attempt to move it or remove its bandages elicited either moans or screams. I thought the child, which was a little over a year old, the most miserable one I had ever seen. I prescribed quarter-grain doses of calomel twice a day, to be given until they produced a laxative effect, then once a day only. Carbolized oxide of zinc ointment $(3 j$ to $3 j$ ) and a borax eye-water were prescribed for external use. Improvement did not take place until the powders had been taken regularly for several days, when it commenced, and, in a few days, rendered the little patient comfortable, and alsle to endure a moderate light. When, later, the calomel treatment was neglected, the case relapsed, in spite of external applications; but a return to it soon cured the eruption, and improved the condition of the patient.

Many other severe cases of the disease have come under my care, and whether the eruption confined itself to the head or ran all over the body, whether the patient was syphilitic or not, strumous or plethoric, they were all similarly affected by calomel. When treated without this remedy, their recovery has usually been very slow, uncertain, and often temporary.

It is an old popular belief, not utterly unfounded, I think, that the rapid drying up of these head eruptions by strong applications does some harm to the system, especially the nervous system. With the aid of calomel and external applications, I have rapidly dried up scores of such head eruptions. without having observed any but good results, and consider the coexisting digestive disorders as the causes of any head symptoms that may arise.

The frequency of occurrence of eczema in infants, the large size and great activity of the liver in early life, and the striking, I might say specific, action of calomel, have led me to associate liver-indigestion with infantile symptoms of eczematous nature in the relation of cause and effect. Even in many syphilitic cases the sallow complexion of the skin, and noctumal restlessness, have seemed to indicate liver disorder of syphilitic origin. In these cases, the alterative powders often produce an amelioration in the skin troubles, sooner than they could through their direct action upon the blood poison; and hence the mercury should be used so as to affect the liver as well as the blood.

A properly regulated diet is necessary, and in some cases is all that need be recommended. But the negative action of diet alone, and the increased debility that would, in the meantime, follow with strumous children, whose disordered and debilitated digestive organs would be slow to assume healthy, vigorous function, makes it very injudicious to wait for such action. Some of my earlier cases were cured without any regulation of diet.

While disordered digestion is usually considered an important factor in certain instances, and a regulated diet, with occasional laxative doses of mercury, are often advised, I know of no authority who has 
considered derangement of the liver, and its accompanying digestive disorders, as the chief predisposing cause, nor of one who has recommended calomel (or its equivalent of blue mass or mercury with chalk) as the chief remedy for the vast majority of cases. In fact, most authors remind the reader that no one remedy can be generally relied upon.

From the fact that many of my earlier cases got well without a regulated diet, that so much calomel produced such prompt relief, and that improved digestive power usually follows, rather than attends, the action of the remedy, I am led to believe that the cure is brought about, not merely by improvement in digestion, but by a removal of waste, irritating materials from the system, which are often the main exciting cause of the eruption. And from the great efficiency of mercurial over other laxatives, I believe that the irritating materials are not only in the retained facal matter, but also in the blood-the products of imperfect digestive assimilation and excretion. There is no doubt that mercurials do much to clear up the urine and to restore normal ingredients to the freces.

Occasional doses of phosphate of sodium, and other saline aperients, act in a similar way, but much less promptly. And the same may be said of castoroil, which has proved efficacious in the hands of $\mathrm{I}$. Duncan Bulkley (Jour. Am. Med. Assoc., July 25).

The strumous and nervous conditions so often observed may, I think, be the causes or effects of the disordered digestive organs, but are seldom the direct causes of the eruptions. Even the beneficial action of cod-liver oil is explainable upon dietetic principles; for pure oil is a much more proper and natural aliment for young children than oatmeal, potatoes, fresh bread, stale cow's milk, and many other table articles of diet that are daily imposed upon their immature stomachs. This oil helps, like castor-oil, to remove fæcal accumulations. With infants fat is a normal ingredient of the healthy fæces.

My excuse for ever resorting to such heroic dosing with calomel, was that a large proportion of my severe cases was traceable to a syphilitic origin; and noticing that these cases bore the remedy so well, I began to try it where I only suspected syphilis, and finally in all cases. I have usually given from a quarter to an eighth-grain powder, according to the age, twice a day, leaving directions that they should be discontinued as soon as purgation commenced, and afterward given as often as the bowels would tolerate them without much disturbance. Their effect, more than the age of the patient, determines their size and frequency of administration.

As children over two and one-half years are very liable to be salivated, I usually give them a single purgative dose of calomel every six or eight days, and trust to diet and other remedies in the meantime. For instance, I was called two years ago to see a boy four years old suffering with patches of eczema about the head and upper part of body, who, although under active medical treatment, had been in about the same condition for several months, except that he was getting worse. While poorly nourished and pale, he was a hearty eater, and was fed upon eggs, potatoes, oatmeal and other stimulating food, with fruit suffcient to keep the bowels regular. I ordered two grains of calomel to be given at bedtime, and some powders containing each one gr. of ext. of pancreas (F. Bros. \& F.), three grs. of bicarb. of sodium, and eight grs. of subnitrate of bismuth: one before each meal. The diet was restricted to milk, beef extract, bread, toast, crackers, rice and fruits. In six days, finding some improvement, I ordered the same medicines and diet. In a week more I found him greatly improved in general health and partly rid of the rash. Recovery was uninterrupted, rapid and permanent, the parents having in the meantime learned how to feed him.

Acute cases may, of course, be greatly benefited by protecting the intlamed skin from all external irritation. This may be done by keeping it constantly covered by simple cerate purified by a few grains of carbolic or salicylic acid to the ounce, or by vaseline, the object being, as already stated, to protect, not to medicate, the skin. In chronic cases, I know of nothing that will allay the itching and stimulate the skin to healthy action as quickly as an ointment composed of one dram of carbolic acid to the ounce of oxide of zinc ointment, constantly applied. I have used this formula in nearly all chronic cases, and have found the combination soothing instead of irritating.

That I am somewhat out of fashion with my calomel I will admit. In one of our latest and best exponents of the present state of dermatological science, I find the following sentence: "Lastly, patients of both classes (of eczema) are to be saved from mercury, arsenic and iodide of potassium." I can only offer as my excuse, that I have found the treatment under consideration almost uniformly successful, and that I would like to do what little I csn to aid others in simplifying the management of this most fickle of all diseases, in finding the centre of this Chinese puzzle of dermatology.

Finally, I would like to say that I do not think it really best to treat the majority of cases in this heroic manner, being usually forced into it by the critical impatience of parents and friends, or by the impossibility of securing a prolonged and intelligent attention to the diet. I would also like to remind any who may chance to thus prescribe calomel, that unless they give it with a proper understanding of the conditions and requirements of the case, they will be just as apt to fail with it as druggists and nurses are apt to fail in curing malaria with quinine, and much more liable to do injury.

3100 Forest Ave.

\section{FEMALE EDUCATION FROM A MEDICAL STANDPOINT. ${ }^{1}$}

BY S. H. HAMILTON, M.D.,

of MoNmouth, IL.L.

The human organization ought to be, and under favoring circumstances is, much like unto a well-constructed and well-regulated piece of machinery, each part of it performing its function by drafts of power 